\title{
Sight for All United: Five Year Impact of a Vision Foundation on its Community
}

\author{
Ankur Parikh ${ }^{1}$; Meredith Spitz; ${ }^{1}$ Cooper T. Johnson ${ }^{1}$; S.A. Erzurum ${ }^{1,2}$ \\ ${ }^{1}$ Northeast Ohio Medical University, Rootstown, $\mathrm{OH}$ \\ ${ }^{2}$ Eye Care Associates, Youngstown, $\mathrm{OH}$ \\ Corresponding Author: Sergul Erzurum, 1075 W Western Reserve Road, Poland, OH 44514, (330) 565-0569, erzurum2020@gmail.com \\ Submitted December 14, 2020 Accepted April 12, 2021 Published June 21, 2021 https://doi.org/10.18061/ojph.v4i1.8074
}

\section{ABSTRACT}

Background: In 2016, Sight for All United (SFAU) was founded in the Mahoning Valley of Ohio with the mission of improving access to care and maximizing the visual potential of the underserved.

Methods: A retrospective chart review was conducted on patients served by SFAU from January 2016 through August 2020. Socioeconomic information, type of service, cost, and dollar amount paid were collected for patients. The data were analyzed with descriptive statistics and mapped with Esri ArcGIS.

Results: A total of 1327 patients received assistance through the medical assistance and school vision programs. In the medical assistance program, 222 patients (mean age 50 years, 57\% female) completed applications and $37 \%$ ( 83 patients) were in a household of 3 or more people. Median yearly income was $\$ 18504,134 \%$ above the federal poverty level by household size. The most common surgical services were cataract surgery (101) and vitreoretinal care (17). The most common medical services were eye exams (79) and spectacles (76). Estimated value of medical services provided was $\$ 367249$; actual cost was $\$ 93746$. The school vision program provided 1105 eye exams, 1514 pairs of spectacles, and 1 cataract surgery with an estimated value of $\$ 133692$.

Conclusion: Sight for All United provided \$500 941 of vision services to its patients since 2016 while dispersing less than $\$ 100000$ of donated dollars through collaboration with eye care providers, community resources, and national foundations. This study demonstrates the impact vision foundations managed by local eye care providers can have on the needs in their community in a cost-effective and efficient way.

Keywords: Nonprofit; Vision; Ophthalmology; Mahoning Valley

\section{INTRODUCTION}

In 1999, the World Health Organization (WHO), in collaboration with over 20 nongovernmental organizations, created the VISION 2020 Global Initiative. Its goal was to eliminate preventable causes of blindness by the year 2020. From 1990 to 2010, the global prevalence of moderate to severe visual impairment in adults over 50 years of age decreased from $3 \%$ to $1.9 \%{ }^{1}$

However, access to vision care remains challenging, even in the United States. Eight million Americans above the age of 40 have vision impairment due to uncorrected refractive error, and over 4 million Americans above the age of 40 have uncorrectable vision impairment, a number that is expected to double by $2050 . .^{2}$
One in 4, or close to 12 million, school-age children in the United States have some form of vision impairment. ${ }^{3}$ The total annual economic burden of eye disorders among the entire United States population is estimated to be over $\$ 138$ billion. ${ }^{4}$

Vision loss is a notable public health crisis in the United States and abroad, and conditions causing vision loss can lead to substantial deterioration in quality of life. ${ }^{5}$ The medical, behavioral, and social consequences of significant vision loss cannot be overstated. Myriad studies have shown the potential consequences of vision loss on independence, mobility, mental health, cognition, and, ultimately, mortality. ${ }^{6}$ 
As a society, we are still dependent on the work of charitable organizations to address the visual needs of our most vulnerable. Their programs are diverse in nature, ranging from comprehensive school vision initiatives to free surgical procedures and complex medical care for adults with vision-threatening disease. ${ }^{7}$ These organizations have an immense proclivity for collaboration. In fact, it is this collaboration that makes charitable vision organizations so unique and effective. Ophthalmologists, optometrists, optical laboratories, and industry corporations have united in an unprecedented way. Vision care providers can identify and treat at-risk or in-need patients while optical laboratories and industry corporations help provide lenses and frames. ${ }^{7}$

The purpose of this study is to describe the experiences on 3 counties in northeast Ohio of a single charitable vision organization, Sight for All United (SFAU), since its inception in 2015.

\section{METHODS}

\section{Setting}

Sight for All United is a 501c3 nonprofit organization based in Youngstown, Ohio, that aims to provide vision services for all members in its community in the tri-county area of Trumbull, Mahoning, and Columbiana, regardless of their ability to pay. This is primarily accomplished through 2 major programs, a medical assistance program and a school vision program. A retrospective chart review was conducted on all patients who received services via these 2 programs from January 2016 through August 2020.

\section{Medical Assistance Program}

\section{Program Design and Participant Characteristics}

When an eye care provider identifies a patient with medical and financial need, a formal medical necessity form is submitted to SFAU on behalf of the patient describing the pathology and services needed. The patient in turn completes a financial application to determine if they qualify for services. The patient provides demographic information, documentation of monthly income and expenses, government benefits (if any), and insurance status. Patients falling below $200 \%$ of the federal poverty level qualify for services.

Once an application is complete with all necessary information, it is reviewed by the executive director. If the medical necessity is solely for spectacles, the application can be reviewed and processed immediately. Via a partnership with a local optical laboratory, SFAU can fill the eye care providers' prescriptions for these patients. If the request involves medical or surgical services, the application is reviewed by the board of directors comprised of eye care practitioners and community leaders.

Patients without insurance can be approved for medical or surgical services up to $\$ 4000$. Often, requests are for assistance paying for high co-pays or deductibles. Treatment is provided by community eye care providers who have agreed to be part of this care network. There are currently 43 eye care providers who work with SFAU, including 21 ophthalmologists and 22 optometrists.

\section{Measures}

For participants in the medical assistance program, socioeconomic information including age, gender, household size, yearly income, zip code, type of service and estimated typical cost, and actual dollar amount paid were collected. For inactive patients or patients who did not ultimately receive services, reasons for inactivity were documented. The estimated value of services provided was calculated using Medicare rates. Percentage of the federal poverty level was calculated using published thresholds from 2020 for participants for which both income data and household size were available. ${ }^{8}$ The value was calculated for each participant and the median of these values was reported.

\section{School Vision Program}

\section{Program Design and Participant Characteristics}

Enrollment in the school vision program is initiated by the school administration and/or nurse. School districts participating included Youngstown City Schools, Liberty Local Schools, Warren City Schools, and Crestview Local Schools.

Students enrolled in kindergarten through eighth grade participate in the screening and subsequent school vision program. Per the vision screening requirements set forth by the Ohio Department of Health, students enrolled in kindergarten or first grade must receive a vision screening. The guideline also requires subsequent screenings in third, fifth, seventh, ninth, and eleventh grades. ${ }^{9}$ School nurses along with community volunteers conduct standardized vision screenings evaluating visual acuity, color vision, and stereoacuity at the participating schools each fall. Parents or guardians of students who fail the screening are educated about the importance of a complete eye examination and given the option to individually seek a medical examination for their child or to participate in the school vision program. If parents choose the school vision program, they complete a consent form for the child to receive an eye examination including pupillary dilation by one of the providers at their school during a designated week.

During the school-based eye exams, any student found to have a refractive error is fit for spectacles the same day. Each child receives 2 pairs of spectacles (a pair for home and a pair for school). These spectacles are dispensed and adjusted at the school. If a child is found to have medical pathology, consultation is recommended, and a form is sent home to the parents. School nurses are expected to follow up on the medical referrals, and SFAU provides assistance with locating a provider or transportation for the children if needed.

\section{Measures}

For participants in the school vision program, aggregate data including number of comprehensive exams and numbers of specta- 
cles dispensed were collected. The estimated value of services provided was calculated using Medicaid rates.

\section{Statistical Analysis}

The data were analyzed using Excel (Microsoft, 2019) and ArcGIS (Esri, 2019). Descriptive statistics, numbers, rates, and proportions were reported for the available data. Provider addresses were plotted against the zip codes of active and inactive patients. Provider addresses were also plotted against the school districts based on the number of students who participated in the program. Providers were coded either as MD (Doctor of Medicine), OD (Doctor of Optometry), or as offices with both types of clinicians. When examining the school district providers, the addresses were coded based on which providers worked with each school district. For example, providers who worked with students from Crestview Schools were grouped together.

\section{RESULTS}

\section{Medical Assistance Program}

Since its inception, 222 patients have been assisted by Sight for All United. Of those, 143 have completed applications, been approved by the board, and received services; 41 have been approved but have not yet received services; and 38 are currently active or at some point in the application process.

Patients who have received or will receive services are on average 50 years of age, $57 \%$ female, $30 \%$ live in a solo household, and
$63 \%$ live in a household with 2 to 4 people. The median income for patients with fully available income data $(\mathrm{n}=145)$ was $\$ 18504$ (on average, $134 \%$ of the federal poverty level).

The most common surgical service provided was cataract surgery ( $n=101$ ). Of note, 16 of these cataract approvals were for co-pay or deductible assistance. Other common surgical services included retinal procedures $(n=17)$ such as laser treatments and intravitreal injections and specialty toric lens implants for patients with severe, monocular astigmatism $(n=11)$. Lower volume surgical services included corneal crosslinking and procedures related to glaucoma and strabismus. The most common medical services included comprehensive eye examinations $(n=79)$ and provision of spectacles $(n=76)$. Patients also received specialty contact lenses for conditions such as keratoconus $(n=7)$, prosthetic eyes $(n=3)$, and medications ( $n=3)$. The total estimated value of these services provided was $\$ 367249$ while the total actual expenditure by SFAU was $\$ 93746$. A summary of the services provided and their estimated value can be seen in Table 1.

There were 126 inactive patients, with the most common reason being an incomplete application ( $n=41,33 \%)$. Other known reasons included denied and withdrawn applications ( $\mathrm{n}=17,14 \%)$, incomplete medical necessity forms $(n=10,8 \%)$, or incomplete income verification $(n=8,6 \%)$.

The zip codes of patients participating in the program along with locations of participating providers can be seen in Figure 1. Zip

\section{Table 1. Services Provided Including Estimated Value}

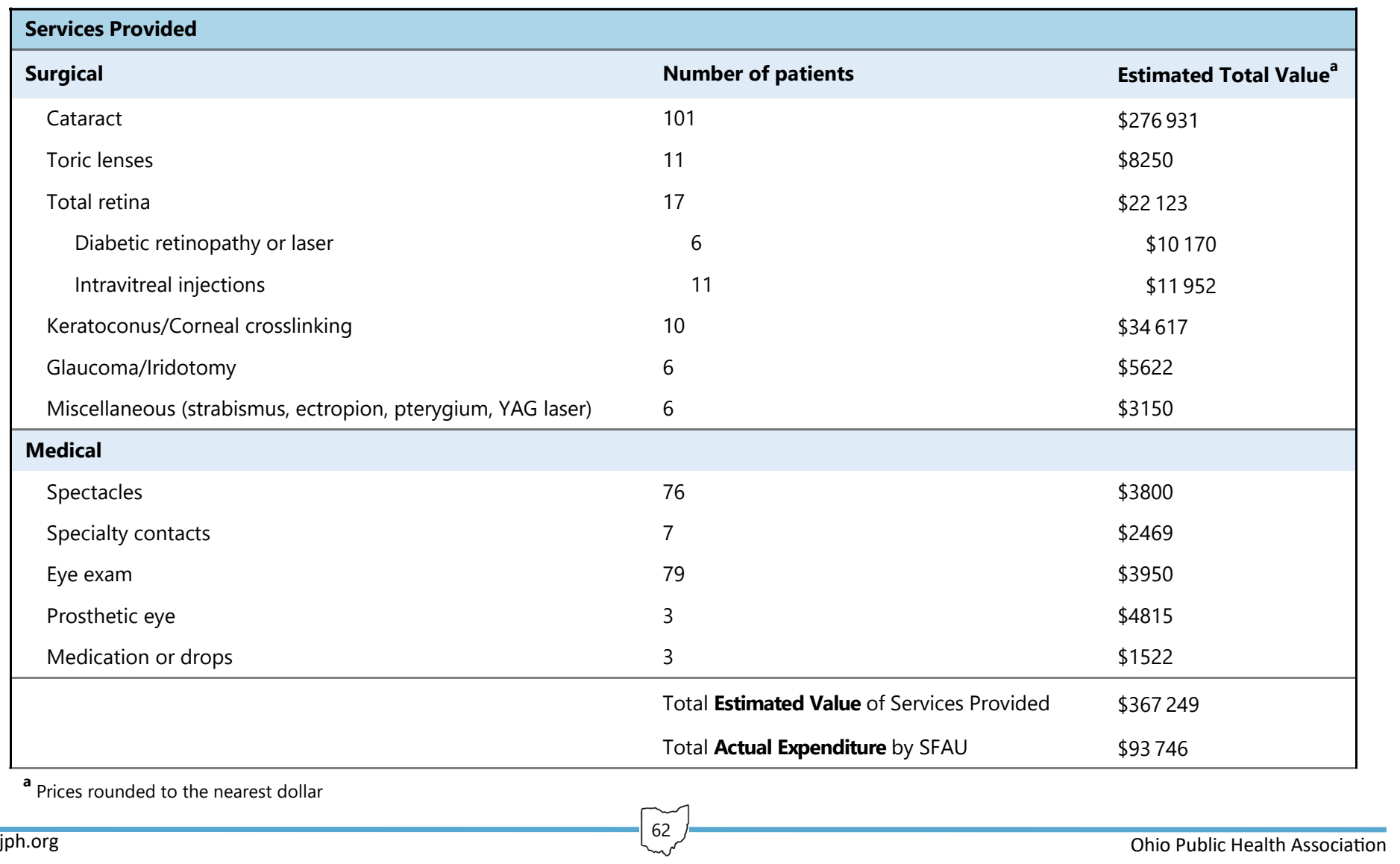




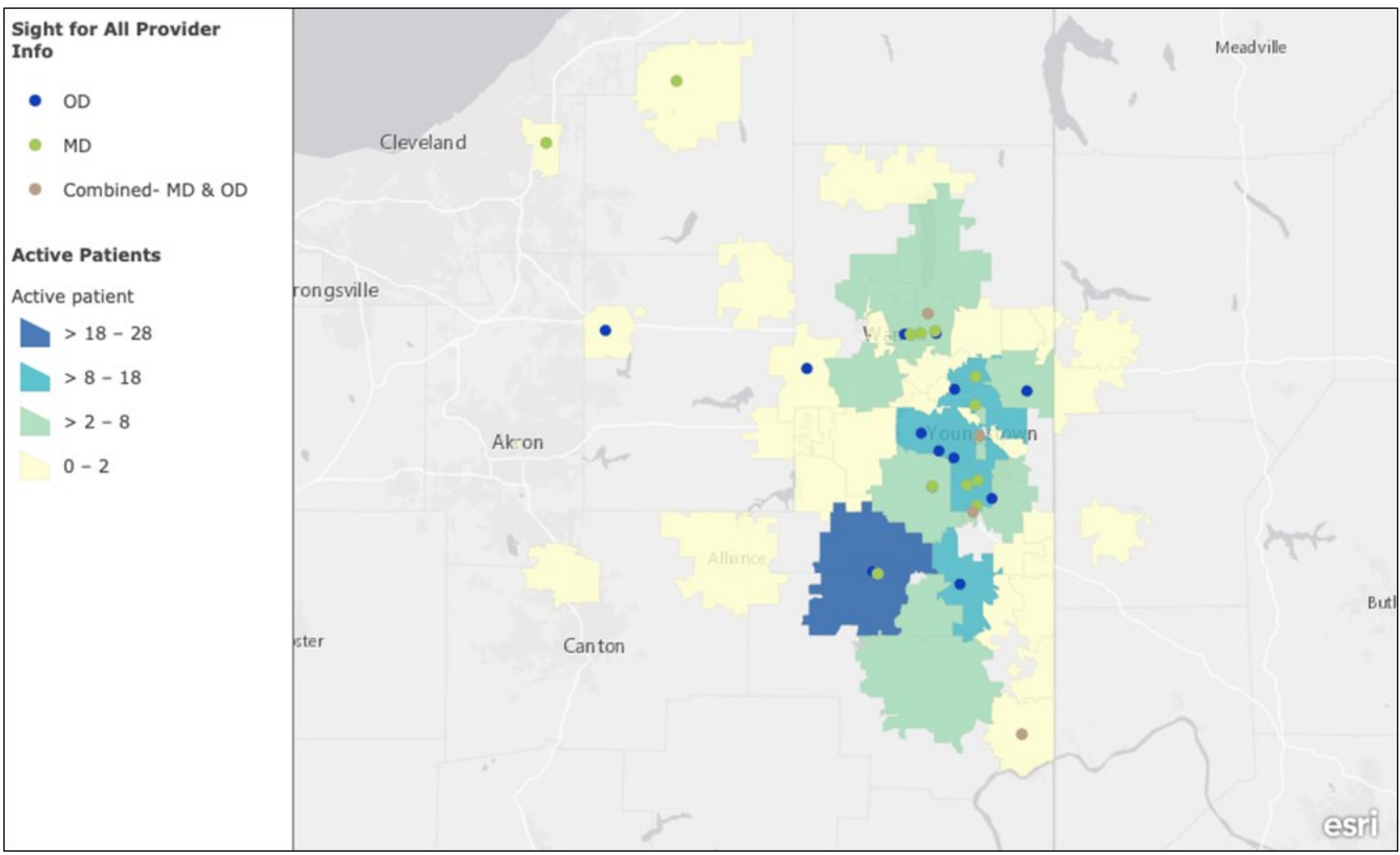

The zip codes with the highest number of patients are dark blue while the zip codes with the fewest patients are cream. Abbreviations: OD, Doctor of Optometry; MD, Doctor of Medicine

Figure 1. Comparison of Active Patient Zip Codes to Provider Zip Addresses

codes with a higher number of patients tended to have providers that are in the same zip code; however, this does not mean that those patients were visiting the nearest provider. There are some outlier zip codes, particularly in the northwest. These zip codes have providers nearby, but few patients. Most of these outlier zip codes were for patients with unusual conditions requiring referral.

\section{$\underline{\text { School Vision Program }}$}

The first school vision program was conducted in 2016 with only 95 students examined. Since that time, 1105 comprehensive eye examinations have been performed with a total estimated value of $\$ 55250$. From these 1105 exams, 378 (34.2\%) children were determined to have a vision impairment correctable with spectacles. In addition, 757 pairs of spectacles have been dispensed with a total estimated value of $\$ 75700$. One child required cataract surgery with an estimated value of $\$ 2742$. The total estimated value of the school vision program over its 4 active years was $\$ 133692$ with a total actual expenditure by SFAU of $\$ 0$ due to collaborations with national vision foundations, local optical laboratories, grants, and school and community organizations. Sight for All United provided and set up all eye examination equipment, eye care providers, oversight of prescriptions ordered, and dispensed all spectacles upon completion. Any spectacles broken or lost were replaced by SFAU's spectacle program at no cost to the student or school. A summary of the number of eye examinations and spectacles provided along with their estimated value can be seen in Table 2 .

A visualization of participating school districts along with the relationship between those school districts and the participating providers can be seen in Figure 2. This displays the providers who work with each school district. While Youngstown City Schools and Liberty Local School District are 2 unique districts, all providers who worked with 1 of these districts also worked with the other district.

\section{Total Value of Services Provided}

In the past 5 years, Sight for All United has served 1476 citizens of the Mahoning Valley community through their medical assistance and school programs by providing services with an estimated total value of $\$ 500941$ and an actual expenditure of $\$ 93746$.

\section{DISCUSSION}

As a result of the programs provided by SFAU, a significant number of patients who otherwise may not have been able to afford or access eye care due to economic or social reasons were provided with medical and surgical services at no cost. It is important to note that 16 patients of the 101 that received cataract surgery had health insurance. However, their significant co-pays or deductibles 


\section{Table 2. School Vision Program Services Provided with Estimated Value}

\begin{tabular}{|lllllll|}
\hline & Number of exams & \$ of exams & $\begin{array}{l}\text { Number of spectacles } \\
\text { (2 pairs per child) }\end{array}$ & \$ of spectacles & Number of misc & \$ of misc \\
\hline 2016 & 95 & $\$ 4750$ & 85 & $\$ 8500$ & 1 (Cataract) \\
2017 & 252 & $\$ 12600$ & 156 & $\$ 15600$ & \\
2018 & 335 & $\$ 16750$ & 232 & $\$ 23200$ & \\
2019 & 423 & $\$ 21150$ & 284 & $\$ 28400$ & \\
\hline Total & $\mathbf{1 1 0 5}$ & $\mathbf{\$ 5 5 2 5 0}$ & $\mathbf{7 5 7}$ & $\mathbf{\$ 7 5 7 0 0}$ & $\mathbf{1}$ & $\mathbf{\$ 2 7 4 2}$ \\
\hline
\end{tabular}

prevented them from receiving the care they needed. The number and range of services provided indicate that there is a large need for vision assistance in this area.

The Mahoning Valley, an area encompassing Mahoning, Trumbull, and Columbiana Counties, is a socioeconomically disadvantaged population. This can often translate to poor health outcomes. Per a report published by the Centers for Disease Control and Prevention (CDC), both Mahoning and Columbiana Counties have a prevalence of vision impairment between $2.4 \%$ and $3.0 \%$. For Trumbull County, the prevalence of vision impairment is between $1.8 \%$ and $2.3 \% .^{10}$ The median household income of these 3 counties, $\$ 48000, \$ 47400$, and $\$ 44900$ respectively, is significantly lower than Ohio's median household income of $\$ 56200.11$ This is especially apparent in the population served by SFAU, whose me- dian household income was just \$18504, or $134 \%$ above the federal poverty level. Age is another indicator that may be correlated to need for vision services, especially cataract surgery. ${ }^{12}$ The proportion of the population over the age of 65 years in these counties, 21\%, 21.6\%, and 20.5\% in Mahoning, Trumbull, and Columbiana respectively, is also significantly higher than the $17.1 \%$ seen throughout the state. ${ }^{11}$

Visual impairment can have a profound impact on a person's quality of life, including their health and wellbeing. ${ }^{6}$ Several factors have been instrumental in the success of the medical assistance program. Sight for All United is in the unique position of being able to operate as a coordinator, negotiator, and payer for services provided by community eye care providers. In its role as coordinator, SFAU can both receive referrals from physicians who have

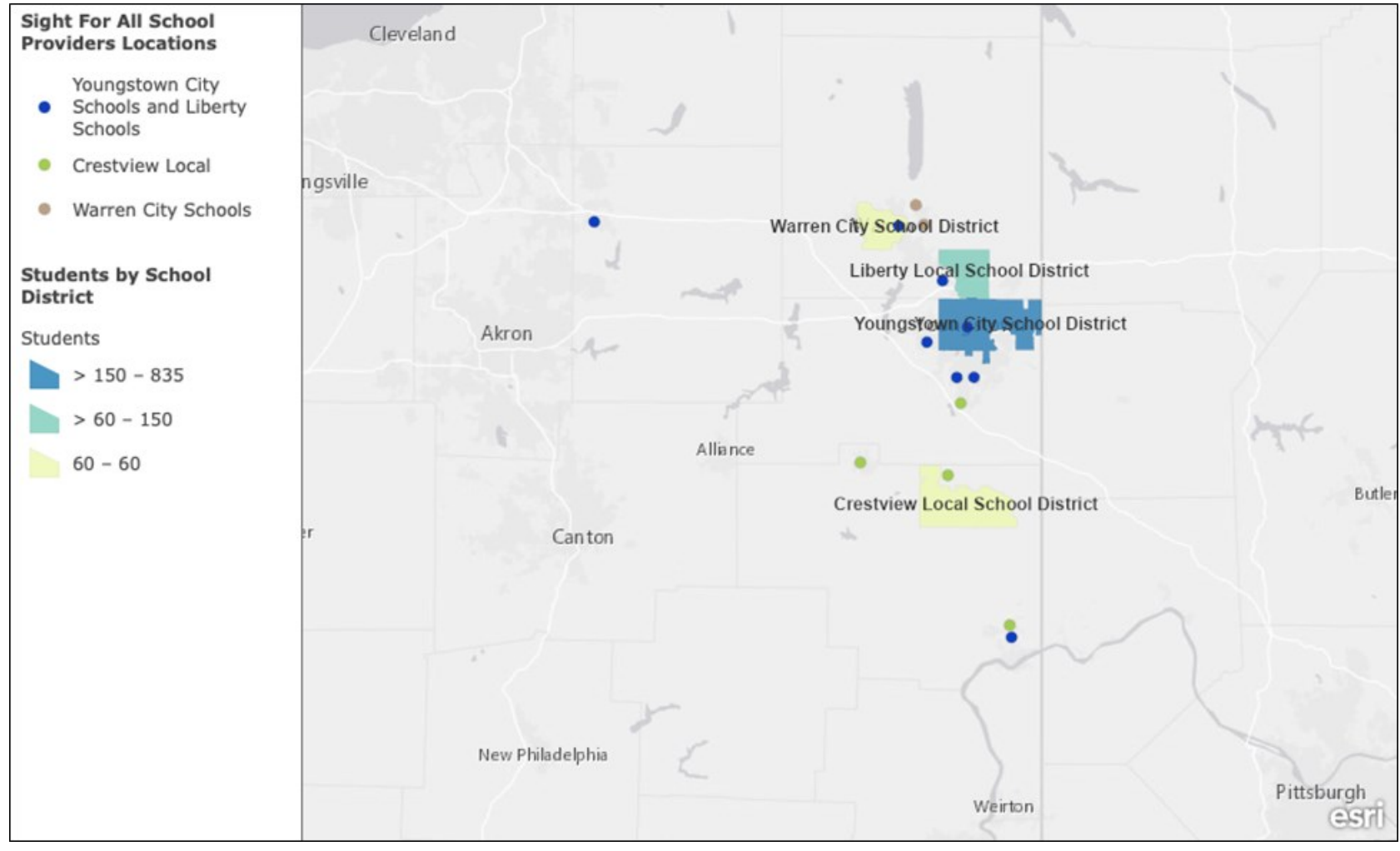

Figure 2. School Districts by Active Students and the Associated Providers 
patients in need and subsequently vet the patients and determine both their economic need and the ultimate cost for the services they require. In its role as a negotiator, SFAU can work with both providers and local and national organizations to deliver the necessary care at reduced costs. Through partnerships with optical laboratories, large vision foundations, and even commercial providers of medical and surgical equipment, they can maximize every dollar received from fundraising and grants. Finally, in their role as payer, they can compensate providers for their service to the community and, as a result, encourage them to continue providing services and advocating for patients in need. Future goals for the medical assistance program include increasing the reach to surrounding communities and increasing the volume of patients served.

While visual impairment has a significant impact on the adult and elderly population, untreated vision impairment also affects children. Prior studies have shown that refractive error and uncorrected visual abnormalities in children can have a significant effect on academic performance and achievement.13-15 Additionally, these visual abnormalities, oftentimes secondary to correctable refractive error, disproportionately affect children from low income and minority families. ${ }^{14}$ While the Ohio Department of Health mandates regular vision screenings for school-age children, one of the biggest roadblocks is optometric and ophthalmic followup care for the children that fail their screenings. ${ }^{9}$ In its vision screening annual report for the 2018-2019 school year, the Ohio Department of Health reported that only $22.5 \%$ of referrals were completed by preschool through twelfth grade students. ${ }^{16}$ It is here that SFAU has been able to have the biggest impact on its community's school-age population. With over four years of implementing and continually improving its school vision program, SFAU has been able to provide eye exams for over 1100 children and provide over 750 pairs of spectacles. Approximately $34 \%$ of children who received an eye examination had a correctable visual deficit and were provided spectacles. As with the medical assistance program, SFAU's relationship with community providers, optical laboratories, and national organizations has been essential to the program's success. Their coordination of these entities along with their on-the-ground knowledge of the Mahoning Valley has allowed the program to be efficiently and effectively executed. In the future, the school vision program will expand to more school districts and include collaboration with school nurses to increase referrals for children with medical issues.

Moving forward, it is critical to continue raising awareness about the effects of visual impairment on health, quality of life, and, for children, academic achievement and future success so that those in need know how and when to reach out for assistance.

\section{PUBLIC HEALTH IMPLICATIONS}

While significant progress in treating vision loss has been made over the past several decades, it remains a significant public health concern. In 2016, the National Academies of Sciences, Engineering, and Medicine (NASEM) issued a report declaring eye health a major public health problem. ${ }^{17}$ The population of Americans with vision loss is expected to increase by nearly 2.5 times by the year 2050, affecting over 7 million people. The projected cost of vision loss is expected to reach nearly $\$ 375$ billion by the year $2050 .^{18}$ However, these are only projections. If we change course and continue supporting and raising awareness about unmet visual needs, the outcome can change. Community organizations will be particularly important in these efforts. By using their specific knowledge and local relationships while building regional and national connections, community organizations can create networks that deliver care to those who need it most.

\section{ACKNOWLEDGMENTS}

Sight for All United would like to thank its partners in sight, especially the Essilor Vision Foundation, Classic Optical Laboratories, United Way of the Mahoning Valley, United Way of Trumbull County, Cafaro Foundation, 00A, and Polena Trust

\section{REFERENCES}

1. Stevens GA, White RA, Flaxman SR, et al. Global prevalence of vision impairment and blindness: magnitude and temporal trends, 19902010. Ophthalmology. 2013;120(12):2377-2384. https://doi.org/10.1016/j.ophtha.2013.05.025

2. Centers for Disease Control and Prevention. Fast facts of common eye disorders. Published June 9, 2020. Accessed August 26, 2020. https://www.cdc.gov/visionhealth/basics/ced/fastfacts.htm

3. Hecker S. New Online Resource to Help Protect Children's Sight Launches from The National Center For Children's Vision And Eye Health at Prevent Blindness and the National Association Of School Nurses. Prevent Blindness; 2016:3. Accessed September 1, 2020. https://preventblindness.org/wp-content/uploads/2016/03/ NASNPBRelease.pdf

4. Wittenborn JS, Zhang X, Feagan CW, et al. The economic burden of vision loss and eye disorders among the United States population younger than 40 years. Ophthalmology. 2013;120(9):1728-1735. https://doi.org/10.1016/j.ophtha.2013.01.068

5. Saaddine JB, Narayan KMV, Vinicor F. Vision loss: a public health problem? Ophthalmology. 2003;110(2):253-254. https://doi.org/10.1016/S0161-6420(02)01839-0

6. National Academies of Sciences E, Division H and M, Practice B on PH and $\mathrm{PH}$, et al. The Impact of Vision Loss. National Academies Press (US); 2016. Accessed December 9, 2020.

http://www.ncbi.nlm.nih.gov/books/NBK402367/

7. United SFA. Sight for All United. Accessed February 20, 2021. https://sightforallunited.com/

8. US Department of Health and Human Services. 2020 Poverty Guidelines. Office of the Assistant Secretary for Planning and Evaluation. Published January 21, 2020. Accessed February 20, 2021.

https://aspe.hhs.gov/2020-poverty-guidelines

9. Ohio Department of Health. Vision Screening Requirements and Guidelines for Preschool and School-aged Children 2017. 2017. Accessed July 30, 2020.

https://odh.ohio.gov/wps/wcm/connect/gov/471c5b34-e547-44fda0a4-f8fbc2190743/Vision-Screening-Requirements-Report-2-18.pdf? 
MOD=AJPERES\&CONVERT_TO $=$ url\&CACHEID=ROOTWORKSPACE.Z1

8_M1HGGIK0N0J000Q09DDDDM3000-471c5b34-e547-44fd-a0a4-

f8fbc2190743-mlCJLCo

10. Centers for Disease Control and Prevention. Vision Health Initiative (VHI) | Ohio State Profile. Published April 25, 2019. Accessed February 20, 2021.

https://www.cdc.gov/visionhealth/data/state-profiles/ohio.htm

11. Compare Counties in Ohio - Mahoning (MH) vs Trumbull (TR) vs Columbiana (CO). County Health Rankings \& Roadmaps. Accessed December 10, 2020.

https://www.countyhealthrankings.org/app/ohio/2020/compare/ additional

12. Hashemi H, Pakzad R, Yekta A, et al. Global and regional prevalence of age-related cataract: a comprehensive systematic review and metaanalysis. Eye. 2020;34(8):1357-1370.

https://doi.org/10.1038/s41433-020-0806-3

13. JBO - Volume 7 - Issue 2 - The vision screening of academically \& behaviorally at-risk pupils | OEP Foundation. Accessed December 11, 2020 .

https://www.oepf.org/journal/pdf/jbo-volume-7-issue-2-visionscreening-academically-behaviorally-risk-pupils

14. Basch CE. Vision and the achievement gap among urban minority youth. J Sch Health. 2011;81(10):599-605.

https://doi.org/10.1111/j.1746-1561.2011.00633.x

15. Maples WC. Visual factors that significantly impact academic performance. Optometry. 2003;74(1):35-49.

16. Ohio Department of Health. ODH Children's Vision Program - Annual Report 2018-2019. Accessed December 6, 2020.

https://odh.ohio.gov/wps/portal/gov/odh/know-our-programs/

children-s-hearing-vision-program/resources/vision-program-annualreport-2018-2019

17. Making Eye Health a Population Health Imperative - NCBI Bookshelf. Accessed December 11, 2020.

https://www.ncbi.nlm.nih.gov/books/NBK385157/

18. Wittenborn JS, Rein D. The Future of Vision: Forecasting the Prevalence and Costs of Vision Problems. NORC at the University of Chicago; 2014. Accessed August 26, 2020.

https://visionimpactinstitute.org/research/the-future-of-visionforecasting-the-prevalence-and-costs-of-vision-problems / 